
\title{
25 Research Square \\ Translation and adaptation of the Learning Organisation Survey for french speaking countries.
}

\author{
Amalia Giuliani Diez \\ National institut of oncology \\ Souadka Amine ( $\nabla$ a.souadka@um5s.net.ma ) \\ National institut of oncology https://orcid.org/0000-0002-1091-9446 \\ Mohammed Anass Majbar \\ National institut of oncology \\ Amine Benkabbou \\ National insitut of oncology \\ Raouf Mohsine \\ National Institut of oncology \\ El Houcine Akhnif \\ Organisation mondiale de la Sante
}

\section{Research article}

Keywords: Translation, Validation Studies, Learning Organization

Posted Date: March 3rd, 2020

DOI: https://doi.org/10.21203/rs.3.rs-15707/v1

License: (1) This work is licensed under a Creative Commons Attribution 4.0 International License. Read Full License 


\section{Abstract}

Background Learning organizations need a diagnostic tool that allows them to assess how well their team, department, or the entire institution is performing, and help them identify areas of improvement. In turn, having that tool in your own language (in this case, French) and adapted to your own context, gives reliability and ease of application. Health organizations are starting to use more and more tools like this that allow them to improve their learning capabilities and, therefore their performance. The aim of the study was the translation of Garvin's et al. Learning Organization Survey into French to evaluate french-speaking health organizations.

Methods the method used to translate the questionnaire was based on Brislin's modified reverse translation technique. Followed by the stage of cross-cultural adaptation through an Atelier of experts, obtaining a pre-final version that was reviewed by a committee of judges with an index of the validity of IVC content $\leq 80 \%$. The French version of the questionnaire proved to be an adequate instrument for the evaluation. The survey was conducted with a sample of 111 workers from the National Oncology Institute of Rabat, who accepted the filling of the survey, $\geq 65 \%$.

Results The established validation criteria were exceeded with results $>80 \%$ in the assessment of experts. We found a good internal consistency, evidenced by a Cronbach's Alpha of $>0.8$ in each block.

Conclusion The questionnaire gathers enough psychometric properties to be considered a useful and reliable tool capable of objectively measuring a french speaking Learning Organization.

\section{Introduction}

Most of low and middle-income countries are engaged in the path to achieving universal health coverage (UHC) [1]. To achieve the UHC countries have to strengthen the functioning of their health services. The global movement toward UHC was translated by the commitment to accelerate the pace of improving the health of the population in all countries by 2030 [2]. Health organizations like hospitals and health centers have a fundamental role to play in improving the overall health performance of any health system. By nature, health systems and health organizations are complex. For this reason researchers started to analyze health systems from the perspective of complexity $[3,4]$. To deal with this complexity health organizations have to develop their strategies and solutions according to collective learning dynamics. The way the knowledge is used as a strategic asset for health organizations is important as well as how to articulate this with the organizational culture [5].

During the last two decades, health researchers became aware of the organizational culture as an important characteristic that may influence the effectiveness and/or success in implementing interventions in different health care settings [6,7].

The concept of Learning Organization (LO) has been developed by and within the productive sector [8-11]. Nevertheless, in health organizations it was already shown that if this concept is duly contextualized, it may enhance organization's learning capabilities and, therefore their performance [12]. In learning organizations the challenge is how to align the use of knowledge with the organization's objectives but also develop the collective learning to be triggered by creating a capacity to impact its performance $[13,14]$. 
If the learning organization concept was developed and used mainly in the hospital setting, most of the applications were in high-income countries hospitals. Achieving the universal health coverage in low and middleincome countries will impose necessarily a transformation at the level of hospitals. Therefore, there is a need to explore the survey as an auditing tool for francophone hospitals to use it as a locomotive for change and transformation.

Since the initial proposals, this area continues developing, as the acceptance of the concept is growing and multitude of different definitions of LO that were described based on "the five disciplines of Senge"[10]. However there are few major convergent factors among them as "that organizations have knowledge, they learn over time, and consider their base knowledge and social capital as something valuable" [15]. According to Garvin, the standard and tools for assessment and implementation of a LO culture were lacking. The reason why he provided a modified framework with a new conceptual model and a diagnostic tool: the Learning Organization Survey [16].

In 2017, Akhnif et al., in an extensive review of the literature on the subject applied in health organizations, concluded that: (1) there are new several instruments that have been developed, (2) but most of the models are based on either the original model of Senge or the modified review of Garvin. (3) There is still a final need to adapt the models to their specific contexts and objectives [16,17].

The survey proposed by Garvin is an important tool that could be used not only as a tool to assess an organization in the direction of a learning one but also each of its questions can lead to action. Given the importance of such tool in guiding the action towards Learning organizations, there is a need for a deep exercice of adaptation for some specific settings. Indeed as demonstrated in the akhnif et al review, the concept was quite well developed in high-income countries and very few applications were in low and middle-income countries. In this same review it was shown that most of the countries that have used the tool are English speaking-countries [17]. Therefore, the aim of this study is to translate and adapt Garvin's LO diagnostic survey based on their modified framework to french speaking health organization. We are using the case of INO hospital of Rabat for this adaptation.

\section{Methodology}

\section{Tool presentation}

The LO survey of Garvin's framework is divided into Three Building Blocks (Table 1). Each one, which represents an area of improvement, is intended to determine in different levels (employees, team, leaders) how the organization is performing.

A first pilot testing of the Learning Organization survey of Garvin et al. showed that the hospital personnel's knowledge of the English language was not sufficient for a proper understanding of the statements. It is therefore translation into French was mandatory to continue for the objective since in the moroccan setting health professionals are trained and are comunicating in French. 


\section{Procedures for translation and adaptation}

The translation and adaptation of the survey was carried out following the steps that are recommended internationally for translation, back-translation, evaluation of translations by a commission of judges, cultural adequacy by the commission of experts and, finally, a pilot test of the pre-final version.

\section{Translation and Back-translation}

The first step in the process was the translation of the English LO survey by Garvin et al. (En1) based on the modified Brislin reverse translation technique [18]. Two Moroccan teachers (fluent in English and French) independently, translated the original survey into French. This is how a first French translation draft was generated (Fr1), which was then back-translated into English (En2) by a native speaker.

During the translation, it was necessary to adapt some terms to maintain the same meaning as the original.

During the back-translation of the survey, no items were found that needed alteration. The questions kept the meaning of the original version. The general coordinator of the project wrote down words and phrases that could imply a divergence of meaning, compared to the back-translated version of the original and, when in doubt, it was discussed with the translator.

\section{Judge's Committee}

The translated and back-translated versions of the survey were presented to a commission of 10 multidisciplinary staff from the INO. As a final part of this process, the content validity of the questions was verified. The content validity index (IVC) was verified for each item of the survey, indicating the percentage of agreement between the specialists, with a pre-established level of IVC $=0.72$ as acceptable.

After the necessary adjustments comparing the original survey (En1) with the back translated version (En2) and the french draft (Fr1); the french final version (FFr) of the survey was generated and assessed in terms of conceptual equivalence, clarity and language and forwarded to the general coordinator of the project who did not indicate adjustments.

\section{Adaptation}

The FFr of the survey were presented to a commission of experts in a workshop for cultural adequacy.

The commission of experts was composed of 12 participants among professors, nurses, medical students and surgical residents, especially selected for their experience and antiquity in the service. All participants received an agenda and material to be discussed one week before to have prior knowledge of the subject.

On the day of the meeting, multidisciplinary groups (a professor, a nurse, a medical student and a surgical resident) were assembled. An introduction to the concept was given and each group, in private, took a Block 
from Gravin survey and decided against each question by common agreement: leave it, remove it or adapt it to the context. Once the group discussion was over, each of the teams presented their decision. All teams together finished discussing and validating the pre-final french survey by mutual agreement (PFV).

\section{Final survey INO}

During this process, all the 55 questions were kept with their respective blocks ( Block 1 "Environnement d'apprentissage favorable"; Block 2 "Processus et pratiques concrètes d'apprentissage"; Block 3 "Leadership qui renforce l'apprentissage"), however the more significant change that the team noted was necessary for adaptation was to turn the questions that have reverse-score in the original Garvin survey into positives, as they considered they were confusing for the respondent and for the analysis.

Besides it, 14 of the questions were modified in terms of words that are usually used in the productive sector, for example: customers, managers, competitors and that were changed to for patients, supervisors and similar units. Concrete learning processes and practices was the block with the maximum of adaptation in this survey.

Another changed was the meaning of the evaluation scale. Although the scale was maintained, its meaning required adaptation to the context of the respondents. In the first two blocks they indicate their agreement with each statement using a seven-level scale, which went from "Désaccord total" (total disagreement) - 1 to "Parfaitement d'accord" (perfectly agree) -7. The third block they indicate their agreement with each statement using a five-level scale, which went from "Jamais" (never) - 1 to "Toujours" (always) - 5.

\section{Pilot test}

The objective of the pilot study was to establish whether the questionnaire could be satisfactorily understood and completed by people from the target population, composed of doctors, nurses, administrators, professors; a group of 10 people evaluated the pre-final translation and made alterations to produce a final version of the questionnaire (FFV). The possibility of adjustments was considered at $15 \%$ or more; in case the participants had difficulty understanding or responding to some item of the instrument.

\section{Setting}

The study was conducted at the National Institute of Oncology (INO), one of the central referral and teaching hospital in Morocco. It has a staff capacity of 456 of which 46 are doctors, 264 nurses, 32 technics, 40 administrative, 74 supporting staff in addition to all medical and nursing student of Mohammed Vth University of Rabat. The hospital has 169 beds, of which are assigned into 3 indoor services activities (surgery, clinical oncology, radiotherapy) and ambulatory chemotherapy unit. The number of patients admission/year was 6489 in 2017.

The inclusion criteria were: (1) employees at the INO (2) present on the days of the survey from the 1st to 31 st August 2019 (3) willing to answer anonymously to this survey. Workers who were absent or on vacation were 
excluded as well as support staff (security and cleaning due to their frequent rotation). The study sample was aleatory, composed of doctors, nurses, administrative and technics, distributed in several units and shifts.

\section{Data collection}

The survey was conducted anonymously and voluntarily; It was distributed to a random sample of 170 INO staff members, from doctors, administrators, residents, professors, nurses, technicians, secretaries. And then collected by members of the research team during August 2019.

Descriptive variables of the population were added such as: age, sex, status, years of experience, years worked in the INO and service they serve.

\section{Analysis}

The data collected were analysed using both Excel ${ }^{\circledR}$ and IBM SPSS Statistics V22.0.

Continuous variables were presented with mean and standard deviations(SD). Categorical variables were presented with percentage.

Normality test of the variables was calculated using Kolmogorov-Smirnov test of normality. Cronbach's alpha coefficients were used to assess reliability and internal consistency for each dimension, each block and the entire survey.

Professions at INO were grouped into three groups (Groups 1, 2 and 3) and the ANOVA test was used to compare descriptive statistics of them and the different Blocks and Dimensions of the survey.

\section{Results}

\section{Descriptive}

Out of the 170 surveys distributed, 111 were collected, with a response rate of $65,2 \%$, from $24 \%$ of the total staff of the INO.

The survey was answered by a population characterized by: 67 women and 44 men, with the mean age of 31,17 $\pm 6,4$. Of them were $36 \%$ Doctors (40), $48 \%$ nurses (53) and $16 \%$ (18) with administrative and technics, distributed in several units and shifts. The mean has 6,7 years of experience and a mean of 4,5 years worked at 
the INO. The population was well distributed in several units and shifts. The average response time was 12,2 min $+/-3$ min.

\section{Reliability results}

The INO survey $(n=111)$ showed an excellent reliability with a Cronbach's alpha of 0.961 . The independent reliability analysis for each block found also a satisfactory Cronbach's alpha score for all three, with a Block 1 of 0.867 and Block 2 and Block 3 with 0.949 and 0.916 respectively, Table 2.

The descriptive statistics for the statements are displayed in Table 2. The means of Q1 to Q 55 was 2,55 $\pm 1,65$ on Q42 to 5,45 $\pm 2,07$ on Q5. Question 5 with the highest overall score is reads as follows: "Le partage des connaissances est valorisé dans cette unité." ("The sharing of knowledge is valued in this unit.") and the lowest score in statement 42, is reads as follows: "Cette unité a des réunions de rencontre et d'apprentissage avec les patients et les citoyens." ("This unit has forums for meetings with and learning from patients and citizens").

Table 3 shows the means of Blocks, calculated by adding all individual scores for each item, ranges between $3.38 \pm 1.03$ (1.00 \pm 5.00$)$ on Block 3 measuring leadership that reinforces learning to $4.02 \pm 0.63(2.45 \pm 6.60)$ on Block 1 measuring a supportive learning environment. A rating higher than 2.0 indicates a more supportive / suitable educational environment. There is no question found with low rating.

In Table 3, the means of the dimensions, calculated by adding all individual scores for each item, ranges between 3,23 on the dimension measuring information transfer (9) to 5,12 on the dimension measuring psychological safety (1). The mean total score of the dimensions is $4,82 \pm 0,45$.

Scores for dimensions and blocks were distributed by groups of professions (Group 1: Doctor, Professor, Resident, Student; Group 2: Nurses; Group 3: Secretary, Administrator, Technician). They were grouped together since they share a common work situation.

INO survey by ANOVA followed by the Holm-Sidak test. The level of a supportive learning environment (Block 1) was generally perceived to be higher by Group 1. However, there was no difference in perception between Group 2 and Group $3(p=0,17)$. Perceived levels of concrete learning processes (Block 2) were higher for Group 1 as compared with Group 2 or Group $3(p=0,001)$. Group 1 also rated leadership that reinforces learning significantly (Block 3) higher than Group 2 or 3 between there were no differences $(p=0,014)$, Table 4.

The mean ranged for group 1, was from 3,98 in dimension measuring "Leadership that reinforces learning" (10) to 5,5 on two dimensions "Psychological safety" (1) and "Openness to new ideas" (3). For Group 2 the mean ranged from 2.6 on the dimension measuring "Leadership that reinforces learning" (9) to 5 on the dimension measuring "Psychological safety" (1). The Group 3 mean ranged from a 2,32 on the dimension measuring 
"Leadership that reinforces learning" (9) to a 5,04 on the dimension measuring "Openness to new ideas" (3), Figure 1.

\section{Discussion}

The objective of this paper is to enhance the tool for francophone countries for better use of the potential of the learning organization concept and tools. Indeed, to trigger the change in health organizations for a better achievement of the UHC objective, health organizations have to develop their abilities to use the knowledge to improve their performance but also to guide transformations. Indeed, it's difficult for health organizations like hospitals to copy and past other hospitals transformational strategies, a contextualization is highly needed. The learning organization framework and tools appear to be good to trigger the change by creating a collective learning dynamic around the action and the use of knowledge. The learning organization culture is also strong in providing possibilities to create collaborative processes. With this paper we simplified the use of the concept for francophone countries so they can introduce change guided by each of the attributes presented in Garvin Framework.

Garvin's survey translated into French can be considered a satisfactory instrument for the evaluation of health learning organizations, as showed high internal consistency, Cronbach's alpha was above 0.961 for the 55 questions. Although some of the dimensions individually remained at 0.6 , the different blocks had satisfactory results with $>0.85$, which could also be explained by some specificities of the context in which the adaptation is conducted

Despite the urgent need for innovation, adaptation, and change in health care, few tools enable researchers or practitioners to assess the extent to which health care facilities perform as learning organizations or the effects of initiatives that require learning.

Many difficulties regarding the assessment of organizational culture lie in the fact that there are an abundance of instruments for assessing and measuring them, applied to a large number of settings, each instrument with their own theoretical background. Moreover, these instruments have mainly been developed for, and tested in, enterprises and high-income settings, resulting in a lack of well established and/or validated instruments for health organizations in low- and middle-income settings [19].

Garvin's et al. revealed three broad factors that are essential for organizational learning and adaptability: a supportive learning environment, concrete learning processes and practices, and leadership behavior that provides reinforcement. And they refer to these as the building blocks of a learning organization. By assessing performance on each building block, you pinpoint areas needing improvement, moving your company that much closer to the learning organization ideal. To know that, they created a diagnostic tool: the Learning Organization Survey, which determines how well your team, department, or entire company is performing with each building block, so after that you identify areas for improvement [16].

In addition to the fact that according to the extensive review of Aknif et al on the subject they concluded that most of the models are based on Garvin, we decided to adapted it to our specific context and objectives [17]. The adaptation we conducted has also a strategic objective to prepare health organizations for a change towards learning organizations. The change can not happen without a deep understanding of the concept, its use and main importantly to facilitate the transition from simple auditing of the organization to a course of action. 
indeed, each of the questions of the tool can lead to a type of action that could be put forward to achieve à LO objective. We know also that if the objective of all health systems is to achieve UHC, paths and ways of concretizing it are not clearly known. The only way to ensure that health organizations are capable of developing efficient strategies for UHC is to invest in learning and collaborative culture.

After adaptation, we can say that health professionals are familiar with the terminology used in the questionnaire and that facilitates the understanding of its content. This assimilation is a sign of the success of the adaptation process.

The application of the instrument could be retained to allow comparisons between services or organizations and also be considered in other groups of workers, (today excluded for lack of full understanding of the French language) with an interview through, rather than self-application.

Although the tool proved to be discriminative and reliable in its entirety, some of the independent dimensions showed no significant difference as the dimensions respect to psychological safety, the appreciation of differences and experimentation. Instead, dimensions such as openness to new ideas and time for reflection showed much discriminative difference.

Results indicate that the respondents obtained the lowest score in the dimension of information transfer (9), with an overall score of 3 out of 7 , indicating a potential area for improvement. For Garvin [11,20], transfer information is part of the concrete steps for learning processes and practices. Without information transfer, knowledge cannot be shared. It is not less than in group 3 and group 2 this gap is bigger. It can only be speculated on what the reasons for this could be, such as academic level or to a centralized hierarchical structure $[21,22]$. The predominant organizational structure for hospitals is, by tradition, mostly bureaucratic, with rigid rules and standard procedures and processes, which leave a narrow margin for the transfer of information [23]. Employees of lower academic level in particular, have little or no influence on decision making so that the information does not reach them more than as specific guidelines [24]. Although this traditional structure is increasingly challenged, there are still many hospitals and organizations in general, in developing countries such as Morocco, which continue with that traditional management structure. But the concrete thing is that noticing this helps to find solutions like open up boundaries and stimulate the exchange of ideas. Boundaries inhibit the flow of information; they keep individuals and groups isolated and reinforce preconceptions. Opening up boundaries, with conferences, meetings, and project teams, which either crossorganizational levels or link the services, patients and suppliers, ensures a fresh flow of ideas and the chance to consider other perspectives[11].

The two dimensions that obtained the highest score, in general, were those related to psychological safety (6) and openings to new ideas (3) with 5 of 7. As Garvin said "to learn, employees cannot fear being belittled or marginalized when they disagree with peers or authority figures, ask naive questions, own up to mistakes, or present a minority viewpoint. Instead, they must be comfortable expressing their thoughts about the work at hand", against that, "they must be encouraged to take risks and explore the untested and unknown" 9 . Finding these two dimensions with high relevance in the population, although it can be further developed, gives hope that the actions that must be made to be LO will have a favorable ground of contention and listening.

Another result that can be considered relevant, but not surprising is that group 1 highlighted an organization with a high level in education and training, 4.94, far from the other two groups. This can be considered in part 
expected, since it is the Medical staff, whether professors, residents or students, who are still bound in permanent training. But in contrast to that, are the nurses the group that declared less formation $[8,18]$.

The short time of reflection was marked in the three groups. Garvin remarks that the first step is to foster an environment that is conducive to learning. There must be time for reflection and analysis. Learning is difficult when employees are harried or rushed; it tends to be driven out by the pressures of the moment $[11,16,25]$. Therefore, when applying the first measures of change this should be a priority.

Finally, with respect to dimension 10 or Block 3 independently, the three groups marked a lack of leadership that reinforces knowledge. Management must be the first to change their behaviors. Since when people in power demonstrated through their own behavior; the willingness to entertain alternative points of view, openness to dialogue and debate, and the importance of using time to identify problems, transfer information, and reflections post-audits; people in the institution will be more encouraged to learn and offer new ideas and options $[20,26]$.

We can refer to the strengths of the study as being the first translation, back-translation of the Garvin tool for French-speaking countries in health organizations. As well and not least important the cultural adaptation for user compression and ensure a reliable answer to the question: is yours an LO?

The representativeness of the sample was another strong point, diverse with different health professionals. The results of this exploratory study provide some evidence of how perceptions vary across organizational levels at the INO concerning the learning organization.

Also, the fact of having added to the study descriptive background data of the population allows a more exhaustive and accurate analysis and define what are the points to cover to become an LO.

The weaknesses of the study were mainly that the survey was not conducted by the total number of INO employees, those who were absent or on vacation did not complete it. In addition to the support staff (security and cleaning due to frequent rotation), their participation should also be considered for future evaluation, since although they are in the institution for a short period of time, they are also an important part of the organization's activities. For a future study, the possibility of including as many people as possible should be evaluated.

Further limitations include biases regarding the people to whom the survey was delivered and who potentially could have answered the questionnaire but did not, which, of course, also adds a level of uncertainty regarding the results.

We could also name the prominent hierarchical structure that can produce a culture of "willingness to please" in the organization that leads the respondents not to score according to their actual perception, but with what they believe the researcher and/or the administration wants them to answer. This could be exaggerated if respondents have confidentiality concerns and fear retribution if they do not score accordingly. This would challenge the credibility of the results, as well as the test itself, and might render the suggested findings invalid. A point to evaluate for future analysis is a preliminary interview with the respondent. 
Perspectives: This will allow its later use as a concrete analysis tool that will delimit actions to move towards a learning organization, facing the challenges of a dynamic environment, such it is the Moroccan health system.

\title{
Conclusions
}

The results of this study support the use of the INO survey as a reliable instrument to evaluate a LO in a health organization in French-speaking countries. Our data suggest that the result of this evaluation could be translated into concrete actions, such as intervention programs that integrate and strengthen a shared vision and team learning to enhance organizational effectiveness in areas where there is a need to improve.

\section{Declarations}

\author{
Abbreviations \\ INO: National Institute of Oncology \\ LO: Learning Organization
}

\section{Ethics approval and consent to participate}

This study was reviewed and approved by the institutional review board of national institut of oncology of rabat Morocco

\section{Consent for publication}

Writting consent was obtained from all participant.

\section{Availability of data and materials}

The datasets used and/or analysed during the current study are available from the corresponding author on reasonable request.

\section{Competings interests}

The authors declare that they have no competing interests.

\section{Funding}

The authors declare that they had no funding.

\section{Author's contributions}

AGD and EA conceptualized the study. AGD and MAM conducted data collection. AGD and AS performed data analysis and prepared the first draft. All authors contributed and approved the final version of the manuscript.

\section{Acknowledgements}


The authors wish to acknowledge the director of the hospital Dr. Jawad Belahcen, who accompanied the project. Also a big thanks to all the services of the National Institute of Oncology of Morocco and specially the Digestive Surgical Oncology team.

\section{Authors information}

Amalia Giuliani Diez agiulianidiez@gmail.com

Digestive Surgical Oncology Department. National Institute of Oncology. Rabat, Morocco.

Amine Souadka; a.souadka@um5s.net.ma

Digestive Surgical Oncology Department. National Institute of Oncology. Rabat, Morocco.

University Mohammed V Souissi, Rabat, Medical School, Digestive Surgical Oncology Department. National Institute of Oncology. Rabat, Morocco.

Mohammed Anass Majbar; anass.majbar@um5s.net.ma

Digestive Surgical Oncology Department. National Institute of Oncology. Rabat, Morocco.

University Mohammed V Souissi, Rabat, Medical School, Digestive Surgical Oncology Department. National Institute of Oncology. Rabat, Morocco.

Amine Benkabbou; a.benkabbou@um5s.net.ma

Digestive Surgical Oncology Department. National Institute of Oncology. Rabat, Morocco.

University Mohammed V Souissi, Rabat, Medical School, Digestive Surgical Oncology Department. National Institute of Oncology. Rabat, Morocco.

Raouf Mohsine; raoufmohsine@gmail.com

Digestive Surgical Oncology Department. National Institute of Oncology. Rabat, Morocco.

University Mohammed V Souissi, Rabat, Medical School, Digestive Surgical Oncology Department. National Institute of Oncology. Rabat, Morocco. 
El Houcine Akhnif. akhnif@who.int

School of Public Health, Rue Lamfadel Cherkaoui, Madinat Al Irfane, BP-6329, Rabat, Morocco.

World Health Organization, Rabat, Morocco

\section{References}

1. World Health Organization. The World Health Report: Health Systems Financing: The Path to Universal Coverage. Geneva: WHO; 2010.

2. The Tokoy declaration on UHC. 2017. https://www.who.int/universal_health_coverage/tokyo-declerationuhc.pdf

3. Plsek PE, Greenhalgh T. Complexity science: the challenge of complexity in health care. BMJ. 2001;323(7313):625.

4. De Savigny D, Blanchet K, Adam T. Applied Systems Thinking for Health Systems Research: A Methodological Handbook. McGraw-Hill Education; 2017. http://researchonline.Ishtm.ac.uk/4646083/. Accessed 20 Feb 2019.

5. Marquardt MJ. Building the Learning Organization: Mastering the Five Elements for Corporate Learning. London: Hachette UK; 2011. https://www. amazon.fr/Building-Learning-Organization-MasteringCorporate/dp/ 1904838324.

6. Vassalou L. The learning organization in health-care services: theory and practice. J Eur Ind Train. 2001;25(7):354-65.

7. Pantouvakis A, Mpogiatzidis P. The impact of internal service quality and learning organization on clinical leaders' job satisfaction in hospital care services. Leadersh Health Serv. 2013; 26 (1):34-49.

8. Kotter JP, Cohen DS. The heart of change. Boston, MA: Harvard Business School Press; 2002.

9. López SP, Peón JMM, Ordás CJV. Human resource management as a determining factor in organizational learning. Manag Learn. 2006;37(2):215-39.

10. Senge PM. The fifth discipline: the art and practice of the learning organization. New York: Random House; 1990.

11. Garvin D. Building a learning organization. Harv Bus Rev. 1993;71(4):78-91.

12. Schilling L, Dearing JW, Staley P, Harvey P, Fahey L, Kuruppu F. Kaiser Permanente's performance improvement system, Part 4: Creating a learning organisation. Jt Comm J Qual Patient Saf. 2011;37(12):532.

13. Peirce JC. The paradox of physicians and administrators in health care organizations. Health Care Manag Rev. 2000;25:7-28.

14. Castaneda, D., Manrique, L. and Cuellar, S. (2018), "Is organizational learning being absorbed by knowledge management? A systematic review", Journal of Knowledge Management, Vol. 22 No. 2, pp. 299-325. 
15. Easterby-Smith, M. and Lyles, M. (Eds), Handbook of Organisational Learning and Knowledge Management, Wiley, Chichester, pp. 1-20.

16. Garvin DA, Edmondson AC, Gino F. Is yours a learning organisation? Harv Bus Rev. 2008;86(3):109.

17. Akhnif E, Macq J, Fakhreddine M.O and Meessen B (2017) “Scoping literature review on the Learning Organisation concept as applied to the health system", Health Research Policy and Systems 15:16 DOI 10.1186/s12961-017-0176-X.

18. Jones PS, Lee JW, Phillips LR, Zhang XE, Jaceldo KB. An adaptation of Brislin's Translation Model for Crosscultural Research. Nurs Res. 2001;50:300-4.

19. Leufvén et al.: Dimensions of Learning Organizations Questionnaire (DLOQ) in a low-resource health care setting in Nepal. Health Research Policy and Systems 2015 13:6.

20. Garvin DA. Learning in Action: A Guide to Putting the Learning Organisation to Work. Cambridge: Harvard Business Press; 2000.

21. Weldy TG, Gillis WE. The learning organization: variations at different organizational levels. Learn Organ. 2010;17(5):455-70.

22. O'Neil J. Participant's guide for interpreting results of the dimensions of the learning organization questionnaire. Adv Dev Hum Resour. 2003;5(2):222-30.

23. Porter-O'Grady T, Malloch K. Quantum Leadership: A Resource for Healthcare Innovation. 2nd ed. Boston: Jones and Bartlett Publishers; 2007.

24. Sangvai D, Lynn M, Michener L. Defining high-performance teams and physician leadership. Physician Exec. 2008;34(2):44-51.

25. Moilanen R. Diagnosing and measuring learning organizations. Learn Organ. 2005;12(1):71-89.

26. Rose, R. C., Kumar, N., \& Pak, O. G. (2009). The Effect Of Organizational Learning On Organizational Commitment, Job Satisfaction And Work Performance. Journal of Applied Business Research (JABR), 25(6).

\section{Tables}

Table 1: Understand the Three Building Blocks of Learning Organizations 6. 


\begin{tabular}{|c|c|}
\hline Building Block & Distinguishing Characteristics \\
\hline $\begin{array}{l}\text { BLOCK } 1 \\
\text { A supportive learning environment }\end{array}$ & $\begin{array}{l}\text { Employees: } \\
\text { - Feel safe disagreeing with others, asking naive questions, owning up to mistakes, and presenting minority viewpoints. } \\
\text { - Recognize the value of opposing ideas. } \\
\text { - Take risks and explore the unknown. } \\
\text { - Take time to review organizational processes. }\end{array}$ \\
\hline $\begin{array}{l}\text { BLOCK } 2 \\
\text { Concrete learning processes }\end{array}$ & $\begin{array}{l}\text { A team or company has formal processes for: } \\
\text { - Generating, collecting, interpreting, and disseminating information. } \\
\text { - Experimenting with new offerings. } \\
\text { - Gathering intelligence on competitors, customers, and technological trends. } \\
\text { - Identifying and solving problems. } \\
\text { - Developing employees' skills. }\end{array}$ \\
\hline $\begin{array}{l}\text { BLOCK } 3 \\
\text { Leadership that reinforces learning }\end{array}$ & $\begin{array}{l}\text { The organization's leaders: } \\
\text { - Demonstrate willingness to entertain alternative viewpoints. } \\
\text { - Signal the importance of spending time on problem identification, knowledge transfer, and reflection. } \\
\text { - Engage in active questioning and listening. }\end{array}$ \\
\hline
\end{tabular}

Table 2: Analysis of Reliability of the survey using Cronbach's alpha test

\begin{tabular}{|l|c|}
\cline { 2 - 2 } \multicolumn{1}{l|}{} & Cronbach's Alpha \\
\hline General & 0,961 \\
\hline BLOC 1 & 0,867 \\
\hline Sécurité psychologique & 0,703 \\
\hline Appréciation des différences & 0,554 \\
\hline Ouverture à de nouvelles idées & 0,703 \\
\hline Temps pour la reflexión & 0,745 \\
\hline BLOC 2 & 0,949 \\
\hline Expérimentation & 0,888 \\
\hline Collecte d'information & 0,612 \\
\hline Analyse & 0,672 \\
\hline Éducation et formation & 0,926 \\
\hline Transfert d'information & 0,955 \\
\hline BLOC 3 & $\mathbf{0 , 9 1 6}$ \\
\hline
\end{tabular}

- INO Survey results $(n=111)$ graded on a seven-point scale for Blocks 1 and 2 ( mean \pm SD ). Levels ranged from 'strongly disagree' $=1$ to 'strongly agree' = 3lock 3 graded on a five-point scale levels ranged from 'Never' = 1 to 'Always' $=5$. 
BLOC 1: Environnement d'apprentissage favorable

Sécurité psychologique

Jans cette unité, il est facile d'exprimer ce que vous pensez.

Jne erreur que vous commettez dans cette unité ne sera pas systématiquement retenu contre vous.

¿es membres de cette unité sont souvent à l'aise pour parler à propos des problèmes et des désaccords.

¿es membres de cette unité partagent volontiers des informations sur ce qui fonctionne et ce qui ne fonctionne pas.

¿e partage des connaissances est valorisé dans cette unité.

Appréciation des différences

¿es différences d'opinion sont les bienvenues dans cette unité.

Гoutes les opinions sont valorisées dans cette unité, mêmes celles qui ne font pas la majorité.

Jette unité à tendance à aborder les différences d'opinion directement avec le groupe, plutôt que de le faire en privé.

Jans cette unité, les personnes sont ouvertes à d'autres façons de travailler.

Juverture à de nouvelles idées

Jans cette unité, les personnes apprécient les nouvelles idées.

Jans cette unité tous écoutent et discutent les idées nouvelles.

Jans cette unité, les personnes sont intéressées par de meilleures façons de faire les choses.

Jans cette unité, les personnes sont ouvertes aux approches inédites.

\section{Temps pour la reflection}

¿es personnes de cette unité ne sont pas particulièrement stressées.

Malgré la charge de travail, les personnes dans cette unité trouvent le temps pour évaluer l'évolution du travail.

Jans cette unité, la pression des délais n'empêche pas de faire du bon travail.

Jans cette unité, les personnes ont le temps de s'investir dans l'auto-amélioration.

Jans cette unité, nous avons le temps de la réflexion.

\section{BLOC 2: Processus et pratiques concrètes d'apprentissage}

Expérimentation

Jette unité expérimente fréquemment de nouvelles façons de travailler.

Jette unité expérimente fréquemment de nouveaux produits ou services.

Jette unité dispose d’un processus bien codifié pour mener et évaluer de nouvelles expériences ou de nouvelles idées.

Jette unité s'engage fréquemment dans de courtes périodes d'essai pour l'exploration de nouvelles idées.

Collecte d'information

Jette unité collecte systématiquement des informations sur des unités similaires.

Jette unité collecte systématiquement des informations sur les tendances économiques et sociales.

Jette unité collecte systématiquement des information sur les patients.

Jette unité collecte systématiquement des information sur les tendances scientifiques.

Jette unité compare fréquemment ses performances aux autres unités similaires.

Jette unité compare fréquemment ses performances à celles des meilleures organisations.

Analyse

Jette unité est engagée dans des débats parfois conflictuels et productifs au cours des discussions.

Jette unité recherche des opinions divergentes au cours des discussions.

Jette unité accepte de revenir sur des points de vue déjà établis au cours des discussions.

Jette unité identifie et discute fréquemment les causes sous-jacentes pouvant affecter les décisions clés.

Jette unité prête attention aux différents points de vue au cours des discussions. 


\begin{tabular}{|c|c|c|}
\hline ¿es employés expérimentés de cette unité reçoivent une formation périodique et de la formation continue. & 108 & $3,82 \pm 2,02$ \\
\hline ¿es employés expérimentés de cette unité reçoivent une formation lorsqu'ils changent de poste. & 106 & $3,31 \pm 2,16$ \\
\hline ¿es employés expérimentés de cette unité reçoivent une formation lorsque de nouvelles initiatives sont lancées. & 106 & $4,14 \pm 2,13$ \\
\hline Jans cette unité, la formation est valorisée. & 110 & $4,43 \pm 2,24$ \\
\hline Jans cette unité, il y a du temps consacré pour les activités d'éducation et de formation. & 110 & $3,76 \pm 2,30$ \\
\hline Transfert d'information & & $3,23 \pm 0,31$ \\
\hline Jette unité a des réunions de rencontre et d'apprentissage avec des experts d'autres départements, équipes ou divisions. & 109 & $3,53 \pm 2,08$ \\
\hline Jette unité a des réunions de rencontre et d'apprentissage avec des experts de l'extérieur de l'hôpital. & 108 & $3,34 \pm 2,05$ \\
\hline Jette unité a des réunions de rencontre et d'apprentissage avec les patients et les citoyens. & 109 & $2,55 \pm 1,65$ \\
\hline Jette unité a des réunions de rencontre et d'apprentissage avec les fournisseurs. & 108 & $3,12 \pm 1,94$ \\
\hline Jette unité partage régulièrement des informations avec des réseaux d'experts au sein de l'organisation. & 106 & $3,26 \pm 2,06$ \\
\hline Jette unité partage régulièrement des informations avec des réseaux d'experts à l'extérieur de l'organisation. & 108 & $3,15 \pm 2,03$ \\
\hline Jette unité communique rapidement et avec précision de nouvelles connaissances aux principaux décideurs. & 108 & $3,40 \pm 2,01$ \\
\hline Jette unité effectue régulièrement des analyses post-audit et post-action. & 103 & $3,52 \pm 2,01$ \\
\hline BLOC 3: Leadership qui renforce l'apprentissage & & $3,59 \pm 0,63$ \\
\hline Mes superviseurs invitent les autres à participer aux discussions. & 111 & $3,23 \pm 1,49$ \\
\hline Mes superviseurs reconnaissent leurs propres limites en matière de savoir, d'information ou d'expertise. & 111 & $3,41 \pm 1,33$ \\
\hline Mes superviseurs posent des questions approfondies. & 110 & $3,48 \pm 1,31$ \\
\hline Mes superviseurs écoutent attentivement. & 110 & $3,54 \pm 1,41$ \\
\hline Mes superviseurs encouragent la diversité des points de vue. & 108 & $3,46 \pm 1,36$ \\
\hline Mes superviseurs fournissent du temps, des ressources et des espaces pour identifier les problèmes et les défis organisationnels. & 111 & $3,34 \pm 1,36$ \\
\hline Mes superviseurs fournissent du temps, des ressources et des espaces pour réfléchir et améliorer les performances passées. & 111 & $3,18 \pm 1,32$ \\
\hline Mes superviseurs acceptent les points de vue différents des leurs. & 110 & $5,14 \pm 1,31$ \\
\hline
\end{tabular}

Table 4: INO perceptions about the Blocks (B) and Dimensions (D) among different groups of professions

\begin{tabular}{|l|l|c|c|c|c|c|c|c|c|c|c|c|c|}
\hline Profession & Variable & B1 & D1 & D2 & D3 & D4 & B2 & D5 & D6 & D7 & D8 & D9 & B3/D10 \\
\hline Groupe 1 & N & 39 & 39 & 39 & 39 & 39 & 32 & 37 & 34 & 37 & 35 & 36 & 38 \\
\hline & Mean & 5,25 & 5,5 & 5,38 & 5,57 & 4,68 & 4,67 & 4,78 & 4,71 & 4,96 & 4,94 & 4,28 & 3,98 \\
\hline & SD & 1,06 & 1,2 & 1,17 & 1,4 & 1,43 & 1,29 & 1,66 & 1,18 & 1,38 & 1,72 & 1,59 & 1,03 \\
\hline Groupe 2 & N & 46 & 51 & 51 & 52 & 48 & 36 & 51 & 45 & 49 & 48 & 47 & 50 \\
\hline & Mean & 4,62 & 5 & 4,71 & 4,77 & 3,95 & 3,62 & 4,36 & 4,06 & 4,3 & 3,12 & 2,6 & 3,34 \\
\hline & SD & 0,94 & 1,16 & 1,1 & 1,19 & 1,36 & 0,94 & 1,49 & 0,97 & 0,98 & 1,45 & 1,45 & 1,1 \\
\hline Groupe 3 & N & 17 & 18 & 19 & 17 & 19 & 13 & 18 & 17 & 19 & 19 & 14 & 18 \\
\hline & Mean & 4,74 & 4,76 & 4,8 & 5,04 & 3,97 & 3,62 & 4,18 & 3,9 & 4,2 & 3,24 & 2,32 & 3,34 \\
\hline & SD & 1,07 & 1,58 & 1,24 & 1,02 & 1,34 & 1,16 & 1,42 & 1,1 & 0,98 & 1,82 & 1,71 & 0,91 \\
\hline$P$ Value & & 0,17 & 0,068 & 0,061 & 0,01 & 0,041 & 0,001 & 0,304 & 0,012 & 0,015 & $<0,001$ & $<0,001$ & 0,014 \\
\hline
\end{tabular}

Group 1: Doctor, Professor, Resident, Student

Group 2: Nurses

Group 3: Secretary, Administrator, Technician

\section{Figures}


- Group 1 - Group 2 - Group 3
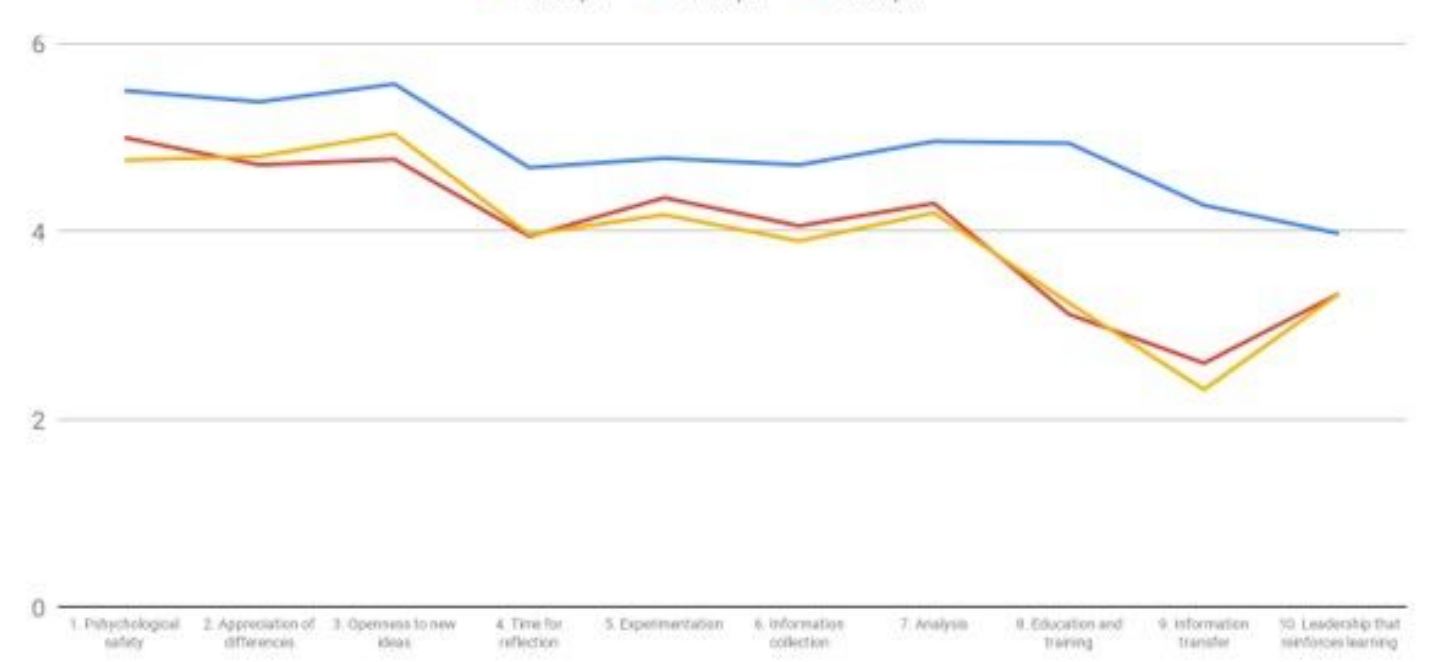

\section{Figure 1}

Diagram showing the distribution of means for each profession as per dimension. 